\title{
Prefrontal cortex projections to the nucleus reuniens suppress freezing following two-way signaled avoidance training
}

\author{
Justin M. Moscarello \\ Department of Psychological and Brain Sciences and Institute for Neuroscience, Texas A\&M University, College Station, \\ Texas 77843-4235, USA
}

\begin{abstract}
Signaled active avoidance (SAA) behavior requires the suppression of defensive reactions, such as freezing, that conflict with the avoidance response. The neural mechanisms of this inhibitory process are not well understood. Here, we demonstrate that ventromedial prefrontal cortex projections to the nucleus reuniens of the thalamus are recruited following SAA training to suppress freezing in rats. This projection may serve as a crucial common pathway for the inhibition of innate defensive reactions that interfere with proactive behavior, thus facilitating adaptive coping.
\end{abstract}

[Supplemental material is available for this article.]

Though freezing is a natural reaction to threatening stimuli, adaptive coping in real-world scenarios often requires flexibility in the face of threat (Moscarello and Maren 2018). If, for instance, a person finds themselves in the path of an oncoming car, the tendency to freeze increases the odds of injury, while the ability to overcome freezing and take action is necessary to stay safe. Signaled active avoidance (SAA) in rat models this adaptive transition from reactive to proactive forms of coping. The subject first associates a conditioned stimulus (CS) with an aversive unconditioned stimulus (US), creating an aversive Pavlovian memory that elicits a constellation of defensive reactions, including freezing. Subsequently, the subject learns that an action performed during the CS causes omission of the US. As the avoidance response is acquired, freezing and other innate defensive reactions to the CS (ultrasonic vocalization, defection) are suppressed (Solomon et al. 1953; Choi et al. 2010; Moscarello and LeDoux 2013) and remain inhibited even when the CS is tested off-baseline in a distinct context that does not allow the avoidance response (Kamin et al. 1963; Starr and Mineka 1977; Mineka and Gino 1980; Moscarello and LeDoux 2014). Though the attenuation of CS-evoked freezing that occurs over the course of SAA training is well-documented, the mechanism underlying this effect is not fully understood.

Prior work demonstrates that inactivation of the ventromedial prefrontal cortex (vmPFC) increases the expression of freezing and attenuates the expression of avoidance in rats (Moscarello and LeDoux 2013). vmPFC projects robustly to the midline thalamus, including the nucleus reuniens (NR) (Vertes 2006; Vertes et al. 2007). This pathway has been shown to inhibit the expression of CS-evoked freezing in an extinction paradigm (Ramanathan et al. 2018a) and to negatively regulate the acquisition and expression of aversive memory in other associative learning paradigms (Davoodi et al. 2011; Xu and Südhof 2013; Ramanathan et al. 2018b; Troyner et al. 2018). On the basis of these results, we hypothesized that the vmPFC-NR projection is recruited by SAA training to suppress CS-evoked freezing. This report

\section{Corresponding author: jmm31@tamu.edu}

Article is online at http://www.learnmem.org/cgi/doi/10.1101/lm.050377.119. describes a series of experiments in which chemogenetic and pharmacological manipulations were used to test this hypothesis in rats.

Three experiments were performed. A detailed account of all materials and procedures is available in Supplemental Methods. In all three experiments, each subject received three daily sessions of two-way SAA training in a standard shuttle box (Coulbourn Instruments). The first trial of the first session of SAA training was a Pavlovian trial, in which each subject received a $15 \mathrm{sec}$ tone CS $(70 \mathrm{~dB}, 2.5 \mathrm{kHz})$ that preceded a foot shock US $(0.7 \mathrm{~mA}$, $1 \mathrm{sec})$ no matter what the subject did during the CS. This was followed by 30 daily avoidance trials, which differed in that subjects could inactivate the tone and avoid the shock if they shuttled across the divided chamber in either direction during the CS.

The day after SAA ended, each subject was placed in a novel context and exposed to 10 CSs identical to those presented during SAA training. This test occurred in a cubical Pavlovian conditioning chamber scented with lavender and fitted with a black Plexiglas floor. Crucially, it lacked the divider necessary for shuttling and thus did not allow the avoidance response. This offbaseline test procedure served to isolate freezing from the avoidance response and thus assessed the role of the vmPFC-NR pathway in the expression of freezing, specifically. Several classic studies have used comparable off-baseline tests to study the influence of SAA training on aversive reactions evoked by the CS (e.g., Kamin et al. 1963; Starr and Mineka 1977; Mineka and Gino 1980). This behavioral design is schematized in Figure 1A.

The initial experiment was designed to confirm the role of vmPFC neurons in the suppression of CS-evoked defensive that results from SAA training. Stereotaxic infusions of adeno-associated virus (AAV5) containing the gene construct for either an inhibitory DREADD (CamKII-hM4Di-HA-mCitrine) or GFP (hSyn-HA-GFP)

(C) 2020 Moscarello This article is distributed exclusively by Cold Spring Harbor Laboratory Press for the first 12 months after the full-issue publication date (see http://learnmem.cshlp.org/site/misc/terms.xhtml). After 12 months, it is available under a Creative Commons License (AttributionNonCommercial 4.0 International), as described at http://creativecommons. org/licenses/by-nc/4.0/ 
A
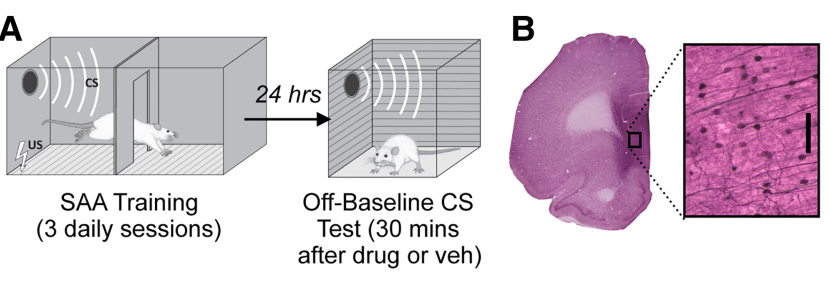

C

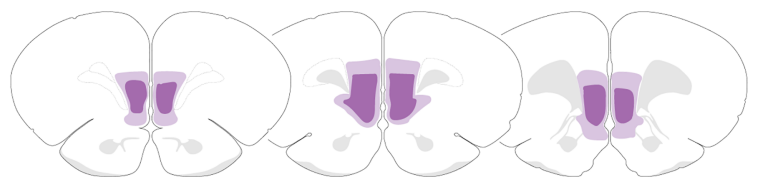

D

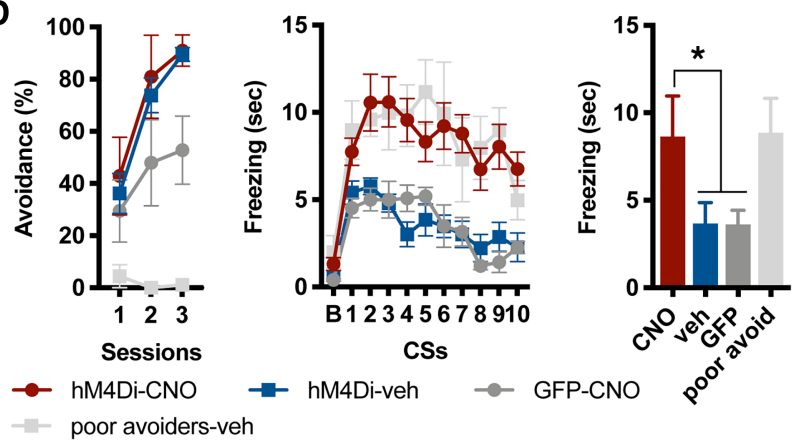

Figure 1. $(A)$ Behavioral design: rats received three sessions of signaled active avoidance (SAA) training. Twenty-four hours after the final session, rats were administered ip CNO or vehicle, placed in a novel context that did not allow the avoidance response and exposed to $10 \mathrm{CSs}$ (off-baseline test). (B) Representative example of hM4Di expression in ventromedial prefrontal cortex (vmPFC), visualized with VIP. Enlarged region shows VIP-labeled vmPFC neurons (scale bar $0.1 \mathrm{~mm}$ ). (C) Greatest/least extent of hM4Di expression in vmPFC. Brain maps adapted from Swanson (2004). (D) Percent total possible avoidance responses across three daily sessions of SAA training (left); freezing during a 15-sec baseline (B), followed by the $10 \mathrm{CSs}$ presented during test (middle); freezing averaged across the $10 \mathrm{CSs}$ presented at test (right). The hM4Di-CNO group showed enhanced freezing relative to other groups, with the exception of poor avoiders (* indicates $P<0.01$ ).

were introduced into vmPFC ( $\mathrm{AP}+2.7, \mathrm{ML} \pm 0.6, \mathrm{DV}-5.4)$. Because both prelimbic and infralimbic PFC have been implicated in SAA (Moscarello and LeDoux 2013; Bravo-Rivera et al. 2014), and because NR-projecting neurons in both prelimbic and infralimbic PFC have been demonstrated to provide equivalent levels of freezing suppression (Ramanathan et al. 2018a), this and the subsequent experiment targeted vmPFC as a whole instead of attempting to manipulate distinct subregions.

After at least $21 \mathrm{~d}$ of recovery, animals received the SAA training paradigm described above. The day after SAA training ended, animals were given an ip injection of CNO $(5 \mathrm{mg} / \mathrm{kg})$ or vehicle (saline with 15\% DMSO). Twenty minutes after injections were administered, subjects received the off-baseline test of the CS. Freezing was scored offline by a trained rater blinded to group. Following the test, animals were transcardially perfused with $4 \%$ paraformaldehyde and their brains processed using immunocytochemical techniques to label hM4Di or GFP expressing neurons with VIP (very intense purple) (Fig. 1B,C).

All groups showed robust avoidance behavior during SAA training, with the exception of poor avoiders, who were defined as subjects from any group that performed six avoidance responses or fewer (i.e., avoided on $\leq 20 \%$ of trials) on the third day of SAA (Fig. 1D, left). This criterion was applied following SAA training (but prior to the off-baseline test), and poor avoiders were aggregated into their own group that received a vehicle injection.
A one-way ANOVA performed on freezing averaged across the 10 CSs presented during the off-baseline test revealed a main effect for group $\left[F_{(3,18)}=16.15, P<0.001\right]$. Tukey's HSD post hoc tests confirmed that the hM4Di-CNO group (subjects receiving CNO inactivation of vmPFC, $n=7$ ) displayed a significant increase in freezing relative to both the hM4Di-veh group (subjects expressing hm4Di in vmPFC that received vehicle injections, $n=7$ ) and the GFP-CNO group (subjects expressing GFP in vmPFC that received CNO, $n=5)(P<0.001$ in both cases; Fig. 1D, right). Notably, the only group from which hM4Di-CNO subjects did not differ were the poor avoiders $(n=3)$, which also showed high levels of freezing. In other words, vmPFC inactivation caused good avoiders to behave like poor avoiders in this test of CS-evoked freezing. Thus, this experiment confirms that the inactivation of vmPFC prevents the suppression of freezing elicited by the CS following SAA training.

The next experiment tested the role of vmPFC projections to NR in the attenuation of CS-evoked freezing. All subjects received intra-vmPFC infusions of AAV5 bearing the gene construct for either hM4Di (hSyn-hM4Di-HA-mCitrine) or GFP (hSyn-HA-GFP). In addition, subjects were also all implanted with a single chronic indwelling cannula aimed at $\mathrm{NR}(\mathrm{AP}-1.7, \mathrm{ML} \pm 2, \mathrm{DV}-7.6$, carrier arm angled at $15^{\circ}$ ). Surgery was followed by a 6-wk recovery period, to allow for DREADD expression in the terminals of vmPFC neurons (Fig. 2A; Supplemental Fig. 1). SAA training and the offbaseline test of CS-evoked freezing were identical to the previous experiment, except that intracranial injections of CNO $(1 \mathrm{mM}$, $0.2 \mu \mathrm{L}$ ) or vehicle were administered directly into NR $20 \mathrm{~min}$ prior to the off-baseline CS test. Following test, subjects were transcardially perfused, their brains isolated, and viral expression labeled with VIP.
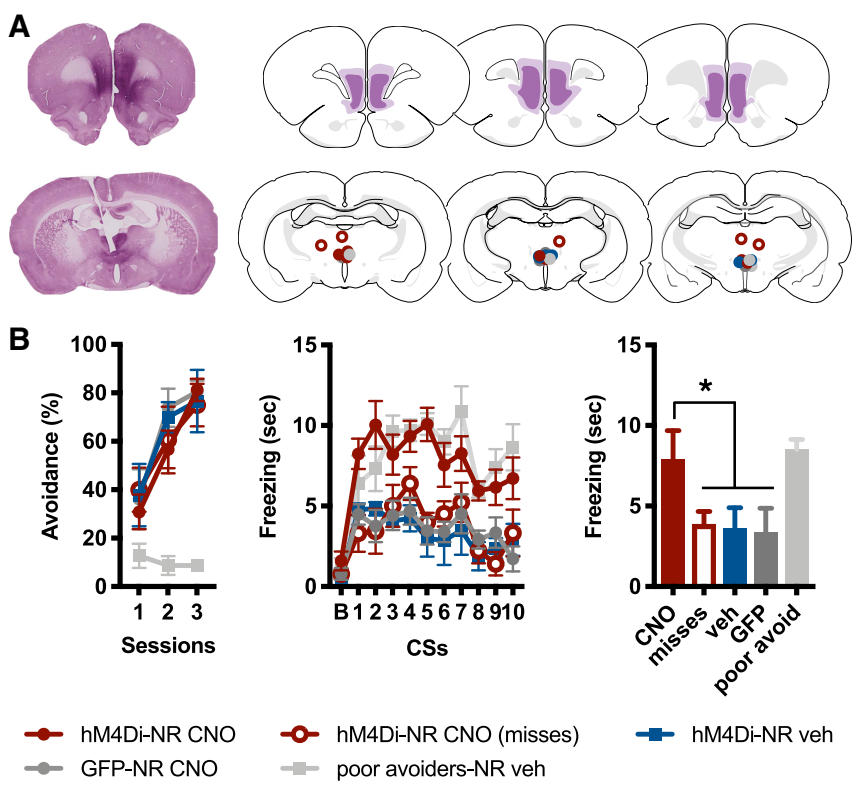

$\rightarrow$ hM4Di-NR veh

Figure 2. (A) Representative example of hM4Di expression in vmPFC, visualized with VIP (top left). Greatest/least extent of hM4Di expression in vmPFC (top right). Representative example of cannula placement, with VIP-labeled vmPFC fibers evident in NR (bottom left). Cannula hits in and around NR (bottom right). Brain maps adapted from Swanson (2004). (B) Percent total possible avoidance responses across three daily sessions of SAA training (left); freezing during a 15-sec baseline (B), followed by the 10 CSs presented during test (middle); freezing averaged across the 10 test CSs (right). The hM4Di-NR CNO group showed enhanced freezing relative to other groups, with the exception of poor avoiders (*indicates $P<0.01$ ). 
As above, subjects displayed robust avoidance during SAA training, with the exception of the poor avoiders (Fig. 2B, left). These subjects were culled from the other groups following SAA and prior to test, using the same performance criterion described in the previous experiment. Similar to the prior experiment, poor avoiders received vehicle injections.

A one-way ANOVA performed on freezing averaged across the 10 CSs presented during the off-baseline test revealed a main effect for group $\left[F_{(4,25)}=21.8, P<0.01\right]$. Tukey's HSD post hoc tests confirmed that the hM4Di-NR CNO group (subjects receiving CNO inactivation of vmPFC terminals in NR, $n=8$ ) displayed a significant increase in freezing relative to the hM4Di-NR veh group (subjects expressing hM4Di in vmPFC neurons that received vehicle injections in NR, $n=6$ ), as well as relative to the hM4Di-NR CNO misses group (subjects with misplaced cannula that received CNO inactivation of vmPFC terminals, $n=5$ ), and finally relative to the GFP-NR CNO group (subjects expressing GFP in vmPFC neurons that received CNO in NR, $n=6)(P<0.01$ in all cases; Fig. $2 \mathrm{~B}$, right). Similar to the previous experiment, the only group from which hm4Di-NR CNO group did not differ were the poor avoiders $(n=$ 5 ), who froze at high levels during the test. In other words, the selective inactivation of vmPFC terminals in NR of good avoiders caused those subjects to produce levels of CS-evoked freezing comparable to poor avoiders. Thus, this specific projection pathway is crucial for the suppression of freezing following SAA training.

Finally, to verify its role, we performed an experiment in which we inactivated NR with muscimol during the offbaseline test of CS-evoked freezing. A pharmacological inactivation technique was chosen for this experiment to corroborate more cutting-edge chemogenetic approaches with a "tried and true" methodology (e.g., prior work demonstrates the effect of vmPFC muscimol inactivation on SAA; Moscarello and LeDoux 2013). Subjects were implanted with a single chronic indwelling cannula aimed at $\mathrm{NR}(\mathrm{AP}-1.7, \mathrm{ML} \pm 2, \mathrm{DV}-7.6$, carrier arm angled at $15^{\circ}$; Fig. $3 \mathrm{~A}$ ) and allowed to recover for at least $21 \mathrm{~d}$. SAA training and the off-baseline test of CS-evoked freezing were identical to the designs described above, except that intracranial injections of muscimol $(0.02 \mu \mathrm{g} / 0.2 \mu \mathrm{L})$ or vehicle (saline) were administered into NR 30 min prior to test. Subjects were then transcardially perfused and their brains isolated, sectioned, and stained with cressyl violet to reveal cannula placement.

All subjects acquired avoidance during SAA training (Fig. 3B, left). There were no poor avoiders in this cohort. This may be due to the fact that poor avoiders occur at a relatively low baseline rate (Galatzer-Levy et al. 2014; Krypotos et al. 2018) and this pharmacological study required fewer groups than our DREADD studies.
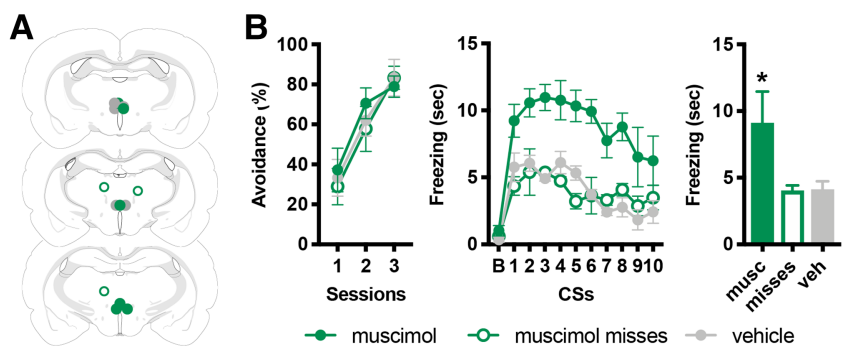

Figure 3. (A) Cannula hits in and around NR. Brain maps adapted from Swanson (2004). (B) Percent total possible avoidance responses across three daily sessions of SAA training (left); freezing during a 15-sec baseline (B), followed by the $10 \mathrm{CSs}$ presented during the test (middle); freezing averaged across the 10 test CSs (right). The muscimol group showed enhanced freezing relative to other groups ( ${ }^{*}$ indicates $P<0.01$ ).
One-way ANOVA performed on freezing averaged across the 10 CSs presented during the off-baseline test revealed a main effect for group $\left[F_{(2,11)}=15.98, P<0.01\right]$. Tukey's post hoc tests revealed that the muscimol group $(n=6)$ froze at higher levels than the vehicle group $(n=6)$ and the muscimol misses group (subjects with misplaced cannula that received muscimol, $n=3$ ) (Fig 3B, right; $P<0.001$ in both cases). Thus, pharmacological inactivation prevents subjects that have acquired the avoidance response from suppressing CS-evoked freezing.

This report demonstrates for the first time that NR-projecting vmPFC neurons underlie a well-documented phenomenon in which SAA training leads to the suppression of behavioral reactions used by many researchers as proxy measures of fear (Solomon et al. 1953; Kamin et al. 1963; Starr and Mineka 1977; Mineka and Gino 1980; Choi et al. 2010; Moscarello and LeDoux 2013; for review of the problematic use of emotion terms to describe animal behavioral models see: LeDoux 2013, 2014, 2017). These results add to a growing body of work describing the role of prefrontal cortex in multiple processes underlying active avoidance behavior (Martinez et al. 2013; Moscarello and LeDoux 2013; Bravo-Rivera et al. 2014; Campese et al. 2015; Diehl et al. 2018; Martínez-Rivera et al. 2019) by illustrating how a specific vmPFC output pathway attenuates freezing even when the CS is presented off-baseline, in an environment distinct from the one in which SAA training occurred.

One possible interpretation of these data is that the vmPFC-NR pathway provides a constitutively active form of freezing inhibition and that inactivation of this projection increases freezing regardless of prior training. While the data set presented here does not speak directly to this possibility, Ramanathan et al. (2018a) demonstrated that pharmacological inactivation of NR and chemogenetic inactivation of NR-projecting vmPFC neurons consistently enhance the expression of CS-evoked freezing only after twenty or more trials of extinction training. In addition, $\mathrm{Xu}$ and Südhof (2013) show no effect on the expression of contextual freezing when the vmPFC-NR projection is permanently silenced following conditioning. These reports, in conjunction with the data presented here, indicate that the vmPFC-NR projection is a common pathway recruited by memory phenomena that suppress freezing instead of providing a tonic or ongoing form of freezing inhibition.

Previous studies demonstrate that the vmPFC-NR pathway functions to integrate contextual information with the acquisition and expression of aversive Pavlovian memories (Davoodi et al. 2011; Xu and Südhof 2013; Ramanathan et al. 2018a,b; Troyner et al. 2018). Much of this work focuses on the role of vmPFC-NR in the expression of aversive associative memories that are specific to particular spatial context or place. In contrast, SAA training suppresses freezing and other defensive reactions across distinct spatial contexts, in a way that is not tied to a particular location (Kamin et al. 1963; Starr and Mineka 1977; Mineka and Gino 1980; Moscarello and LeDoux 2013). One possible interpretation is that learned control over the US creates an internal or cognitive context (for review of contextual processing see: Maren et al. 2013), engaging the vmPFC-NR projection to inhibit defensive reactions such as freezing across different spatial environments. This is consistent with research on learned helplessness, which demonstrates that prior experience of control over shock duration in one environment can reduce CS-evoked freezing when shock is later paired with a Pavlovian cue in a distinct experimental setting (Baratta et al. 2008; Maier and Seligman 2016). Indeed, the effect of controllability can even generalize from appetitive to aversive behavior, as illustrated by a study demonstrating that control over food and water delivery leads to reduced thigmotaxis in an open field assay (Joffe et al. 1973). The function of such an internal context may be explained using the concept of agency, in which 
past experiences of control allow the organism to infer that proactive, as opposed to reactive, behavioral strategies will carry an adaptive benefit (Moscarello and Hartley 2017). In other words, learned control in SAA and other paradigms may create a context that engages the vmPFC-NR pathway to suppress defensive behaviors that interfere with the ability to explore and exploit the environment.

While the majority of subjects acquire active avoidance behavior, poor avoiders are unable to make the transition from freezing to avoidance (Choi et al. 2010; Lázaro-Muñoz et al. 2010; Galatzer-Levy et al. 2014). The neurobiological process that prevents some subjects from making this behavioral shift is not well-characterized. Previous work demonstrates that good avoiders show higher levels of cFos immunoreactivity in vmPFC relative to poor avoiders (Martinez et al. 2013), suggesting that poor avoiders are unable to recruit the vmPFC and, potentially, the projections to NR that our current data suggest are necessary to suppress freezing. In addition, a neighboring corticothalamic projection, originating in the prelimbic subregion of $\mathrm{mPFC}$ and terminating in the paraventricular nucleus (PVN) of the dorsal midline thalamus, plays an opposing role by promoting the expression of conditioned freezing (Do-Monte et al. 2015). Thus, the failure to transition from freezing to avoidance may be due to a maladaptive balance of activity among mPFC projections and their targets along the dorsal-ventral axis of the midline thalamus, in which PVN-projecting neurons remain persistently active and NR-projections neurons are not recruited, biasing the subject to a reactive behavioral strategy dominated by freezing.

In conclusion, I demonstrate that the vmPFC-NR pathway is recruited following SAA training to suppress conditioned freezing. Because other research demonstrates the critical role played by this projection in the contextual modulation of aversive memory, I argue that control over the US may create a cognitive context that alters the retrieval and/or expression of the CS-US association formed early on in SAA training. Recent evidence indicates that the diminution of CS-evoked conditioned reactions (skin conductance response) also occurs in humans performing in an SAA paradigm; this effect is associated with increased activity in vmPFC (Boeke et al. 2017). The pathway described in this report may have a conserved function, modulating the expression of conditioned defensive reactions in multiple species and facilitating adaptive coping in a complex, fluid environment.

\section{Acknowledgments}

Support for this work came from NIDA grant R01 DA044445 and from the Vulnerable Brain Project. The author would also like to acknowledge Claudia Farb for her assistance with tissue processing and immunocytochemistry.

\section{References}

Baratta MV, Lucero TR, Amat J, Watkins LR, Maier SF. 2008. Role of the ventral medial prefrontal cortex in mediating behavioral control-induced reduction of later conditioned fear. Learn Mem 15: 84-87. doi:10.1101/lm.800308

Boeke EA, Moscarello J, LeDoux JE, Phelps EA, Hartley CA. 2017. Active avoidance: neural mechanisms and attenuation of Pavlovian conditioned responding. J Neurosci 37: 4808-4818. doi:10.1523/ JNEUROSCI.3261-16.2017

Bravo-Rivera C, Roman-Ortiz C, Brignoni-Perez E, Sotres-Bayon F, Quirk GJ. 2014. Neural structures mediating expression and extinction of platform-mediated avoidance. J Neurosci 34: 9736-9742. doi:10.1523/ JNEUROSCI.0191-14.2014

Campese VD, Sears RM, Moscarello JM, Diaz-Mataix L, Cain CK, LeDoux JE. 2015. The neural foundations of reaction and action in aversive motivation. In Behavioral neuroscience of motivation: current topics in behavioral neurosciences (ed. Simpson E, Balsam P), vol. 27, pp. 171-195. Springer, Cham.

Choi JS, Cain CK, LeDoux JE. 2010. The role of amygdala nuclei in the expression of auditory signaled two-way active avoidance in rats. Learn Mem 17: 139-147. doi:10.1101/lm.1676610

Davoodi FG, Motamedi F, Akbari E, Ghanbarian E, Jila B. 2011. Effects of reversible inactivation of reuniens nucleus on memory processing in a passive avoidance task. Behav Brain Res 221: 1-6. doi:10.1016/j.bbr.2011 .02 .020

Diehl MM, Bravo-Rivera C, Rodriguez-Romaguera J, Pagan-Rivera PA, Burgos-Robles A, Roman-Ortiz C, Quirk GJ. 2018. Active avoidance requires inhibitory signaling in the rodent prelimbic prefrontal cortex. Elife doi: 10.7554/eLife.34657.

Do-Monte FH, Quiñones-Laracuente K, Quirk GJ. 2015. A temporal shift in the circuits mediating retrieval of fear memory. Nature 519: 460-463. doi: $10.1038 /$ nature 14030

Galatzer-Levy IR, Moscarello JM, Blessing EM, Klein J, Cain CK, LeDoux JE. 2014. Heterogeneity in signaled active avoidance learning: substantive and methodological relevance of diversity in instrumental defensive responses to threat cues. Front Syst Neurosci 8: 179. doi:10.3389/fnsys .2014 .00179

Joffe JM, Rawson RA, Mulick JA. 1973. Control of their environment reduces emotionality in rats. Science 180: 1383-1384. doi:10.1126/science.180 .4093 .1383

Kamin LJ, Brimer CJ, Black AH. 1963. Conditioned suppression as a monitor of fear of the CS in the course of avoidance training. J Comp Physiol Psychol 56: 497-501. doi:10.1037/h0047966

Krypotos AM, Moscarello JM, Sears RM, LeDoux JE, Galatzer-Levy I. 2018. A principled method to identify individual differences and behavioral shifts in signaled active avoidance. Learn Mem 25: 564-568. doi:10 $.1101 / \mathrm{lm} .047399 .118$

Lázaro-Muñoz G, LeDoux JE, Cain CK. 2010. Sidman instrumental avoidance initially depends on lateral and basal amygdala and is constrained by central amygdala-mediated Pavlovian processes. Biol Psychiatry 67: 1120-1127. doi:10.1016/j.biopsych.2009.12.002

LeDoux JE. 2013. The slippery slope of fear. Trends Cog Sci 17: 155-156. doi:10.1016/j.tics.2013.02.004

LeDoux JE. 2014. Coming to terms with fear. Proc Natl Acad Sci 111: 2871-2878. doi:10.1073/pnas.1400335111

LeDoux JE. 2017. Semantics, surplus meaning, and the science of fear. Trends Cogn Sci 21: 303-306. doi:10.1016/j.tics.2017.02.004

Maier SF, Seligman ME. 2016. Learned helplessness at fifty: insights from neuroscience. Psychol Rev 123: 349-367. doi:10.1037/rev0000033

Maren S, Phan KL, Liberzon I. 2013. The contextual brain: implications for fear conditioning, extinction and psychopathology. Nat Rev Neurosci 14: 417-428. doi:10.1038/nrn3492

Martinez RC, Gupta N, Lázaro-Muñoz G, Sears RM, Kim S, Moscarello JM, LeDoux JE, Cain CK. 2013. Active vs. reactive threat responding is associated with differential c-Fos expression in specific regions of amygdala and prefrontal cortex. Learn Mem 20: 446-452. doi:10.1101/ lm.031047.113

Martínez-Rivera FJ, Bravo-Rivera C, Velázquez-Díaz CD, MontesinosCartagena M, Quirk GJ. 2019. Prefrontal circuits signaling active avoidance retrieval and extinction. Psychopharmacology (Berl) 236: 399406. doi:10.1007/s00213-018-5012-7

Mineka S, Gino A. 1980. Dissociation between conditioned emotional response and extended avoidance performance. Learn Motiv 11: 476-502. doi:10.1016/0023-9690(80)90029-6

Moscarello JM, Hartley CA. 2017. Agency and the calibration of motivated behavior. Trends Cogn Sci 21: 725-735. doi:10.1016/j.tics.2017.06.008

Moscarello JM, LeDoux JE. 2013. Active avoidance learning requires prefrontal suppression of amygdala-mediated defensive reactions. J Neurosci 33: 3815-3823. doi:10.1523/JNEUROSCI.2596-12.2013

Moscarello JM, LeDoux JE. 2014. Diverse effects of conditioned threat stimuli on behavior. Cold Spring Harb Symp Quant Biol 79: 11-19. doi:10 $.1101 /$ sqb.2014.79.024968

Moscarello JM, Maren S. 2018. Flexibility in the face of fear: hippocampal-prefrontal regulation of fear and avoidance. Curr Opin Behav Sci 19: 44-49. doi:10.1016/j.cobeha.2017.09.010

Ramanathan KR, Jin J, Giustino TF, Payne MR, Maren S. 2018a. Prefrontal projections to the thalamic nucleus reuniens mediate fear extinction. Nat Commun 9: 4527-4512. doi:10.1038/s41467-018-06970-z

Ramanathan KR, Ressler RL, Jin J, Maren S. 2018b. Nucleus reuniens is required for encoding and retrieving precise, hippocampal-dependent contextual fear memories in rats. J Neurosci 38: 9925-9933. doi:10.1523/ JNEUROSCI.1429-18.2018

Solomon RL, Kamin LJ, Wynne LC. 1953. Traumatic avoidance learning: the outcomes of several extinction procedures with dogs. J Abnorm Soc Psychol 48: 291-302. doi:10.1037/h0058943

Starr MD, Mineka S. 1977. Determinants of fear over the course of avoidance learning. Learn Motiv 8: 332-350. doi:10.1016/0023-9690(77)90056-X 
Swanson LW. 2004. Brain maps: structure of the rat brain, 3rd ed. Elsevier, Oxford.

Troyner F, Bicca MA, Bertoglio LJ. 2018. Necleus reuniens of the thalamus controls fear memory intensity, specificity, and long-term maintenance during consolidation. Hippocampus 28: 602-616. doi: 10.1002/hipo .22964 .

Vertes RP. 2006. Interactions among the medial prefrontal cortex, hippocampus and midline thalamus in emotional and cognitive processing in the rat. Neuroscience 142: 1-20. doi:10.1016/j .neuroscience.2006.06.027
Vertes RP, Hoover WB, Szigeti-Buck K, Leranth C. 2007. Nucleus reuniens of the midline thalamus: link between the medial prefrontal cortex and hippocampus. Brain Res Bull 71: 601-609. doi:10.1016/j.brainresbull .2006 .12 .002

Xu W, Südhof TC. 2013. A neural circuit for memory specificity and generalization. Science 339: 1290-1295. doi:10.1126/science.1229534

Received August 2, 2019; accepted in revised form November 30, 2019. 


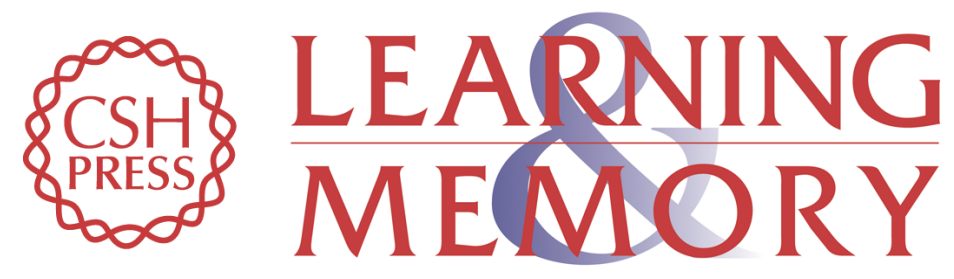

\section{Prefrontal cortex projections to the nucleus reuniens suppress freezing following two-way signaled avoidance training}

Justin M. Moscarello

Learn. Mem. 2020, 27:

Access the most recent version at doi:10.1101/Im.050377.119

\section{Supplemental http://learnmem.cshlp.org/content/suppl/2020/01/30/27.3.119.DC1 Material}

References This article cites 33 articles, 12 of which can be accessed free at: http://learnmem.cshlp.org/content/27/3/119.full.html\#ref-list-1

Creative This article is distributed exclusively by Cold Spring Harbor Laboratory Press for the Commons first 12 months after the full-issue publication date (see

License http://learnmem.cshlp.org/site/misc/terms.xhtml). After 12 months, it is available under a Creative Commons License (Attribution-NonCommercial 4.0 International), as described at http://creativecommons.org/licenses/by-nc/4.0/

Email Alerting Receive free email alerts when new articles cite this article - sign up in the box at the Service top right corner of the article or click here. 